\title{
Influência do número de animais e tipo de comedouro na unidade experimental sobreas exigências nutricionais e composição de carcaça de suínos em terminação ${ }^{1}$
}

\section{Francisco Carlos de Oliveira Silva ${ }^{2}$, Juarez Lopes Donzele ${ }^{3}$, Rita Flávia Miranda de Oliveira ${ }^{3}$ Aloízio Soares Ferreira ${ }^{3}$, Alberto Marcatti Neto ${ }^{4}$, Eriane de Paula ${ }^{5}$}

\author{
${ }^{1}$ Financiado pelo CNPq. \\ 2 EPAMIG. \\ ${ }^{3}$ DZO - UFV. \\ ${ }^{4}$ Pesquisador da EPAMIG - Belo Horizonte. \\ ${ }^{5}$ Curso de graduação em Zootecnia - UFV.
}

RESUMO - Objetivou-se avaliar os efeitos do número de animais por unidade experimental e do tipo de comedouro sobre as exigências nutricionais e as características de carcaça de suínos dos 60 aos 95 kg. Utilizaram-se 704 suínos, machos castrados, com 59,84 $\pm 1,67 \mathrm{~kg}$ de peso corporal, distribuídos em delineamento experimental em esquema de parcelas subdivididas, com diferentes números de animais por unidade experimental nas parcelas e, nas subparcelas, um esquema fatorial $2 \times 4$, com dois tipos de comedouro e quatro níveis de lisina digestível na ração (0,75; 0,85; 0,95\% e 1,05\%), em delineamento de blocos ao acaso com quatro repetições. Não ocorreu interação significativa entre níveis de lisina, tipo de comedouro e número de animais na unidade experimental para os consumos de ração e de lisina, o ganho de peso e a conversão alimentar. O ganho de peso e o consumo de lisina aumentaram de forma linear com o aumento dos níveis de lisina digestível. A conversão alimentar melhorou de forma linear, contudo o modelo "Linear Response Plateau” foi o que melhor se ajustou aos dados, estimando em 0,96\% o nível de lisina digestível, correspondente a um consumo diário de $26,1 \mathrm{~g}$, a partir do qual ocorreu "plateau". O uso de dois animais por unidade experimental proporcionou melhores resultados de ganho de peso e conversão alimentar. Houve interação tipo de comedouro $\times$ número de animais na unidade experimental, de modo que o rendimento de carcaça e a quantidade de carne magra reduziram com o uso dos comedouros conjugados com bebedouros nas unidades experimentais com dois animais, mas não variaram com o tipo de comedouro nas unidades experimentais com 20 animais. Suínos dos 60 aos 95 kg exigem, respectivamente, 1,05 e 0,96\% de lisina digestível para melhores resultados de ganho de peso e conversão alimentar, independentemente do tipo de comedouro e do número de animais na unidade experimental. Nas unidades experimentais com dois suínos, ocorrem diferenças no desempenho, com maior ganho de peso e melhor conversão alimentar, mas nenhuma alteração significativa nos consumos de ração e de lisina.

Palavras-chave: aminoácido digestível, exigência, nutrição, suínos em terminação

\section{Influence of the number of animals and type of feeder in the experimental unit on the nutritional requirement and carcass composition of finishing pigs}

\begin{abstract}
With the objective of evaluating the effects of the number of animals per experimental unit and the type of feeder on the nutritional requirement and carcass characteristics of pigs from 60 to $95 \mathrm{~kg}, 704$ castrated male pigs with initial body weight of $59.84 \pm 1.67 \mathrm{~kg}$ were used. The animals were distributed in a randomized experimental design subdivided into parcels, with different number of animals per experimental unit (EU) and in the subplots, a $2 \times 4$ factorial scheme, with 2 types of feeders and 4 levels of digestible lysine in the diet $(0.75,0.85,0.95$ and 1.05\%), in a completely randomized block design with 4 replicates. There was no significant interaction between lysine levels, type of feeder and number of animals per EU on feed intake (DFI), lysine intake (DLI), weight gain (DWG) and feed conversion (FC). It was verified that DWG and DLI increased linearly with increased digestible lysine levels. It was verified that FC improved linearly, although the "Linear Response Plateau" model was the best that adjusted to the data, estimating in $0.96 \%$ the level of digestible lysine, corresponding to a daily consumption of $26.1 \mathrm{~g}$ after the start of the "plateau". The use of two animals/EU provided better DWG and FC results. An interaction between the type of feeder and the number of animals per EU was observed, the carcass gain (CG) and the lean meat quantity (LMQ) were reduced with the use of feeders conjugated with nipple drinkers in the EU with two animals; however, no variation was observed with the type of feeder when the EU presented 20 animals. It could be concluded that pigs from 60 to $95 \mathrm{~kg}$ require, respectively 1.05 and $0.96 \%$ of digestible lysine for better DWG and FC performance, regardless of type of feeder and number of animals per EU; and in the EU with two pigs, the animals show changes on their performance, increasing DWG and improving FC, without significant changes on DFI and DLI.
\end{abstract}

Key Words: digestible amino acid, finishing pigs, nutrition, requirement 


\section{Introdução}

Tem sido referendado grande número de fatores que influenciam a exigência de aminoácidos de suínos, entre eles, genética, sexo, concentração de energia e proteína na ração, frequência de alimentação, critério de respostas, temperatura, doenças, espaço no comedouro e densidade animal, que, segundo Edmonds et al. (1998), podem afetar o consumo e o potencial de deposição de carne magra e influenciar as exigências de aminoácidos.

Por outro lado, as pesquisas em nutrição animal são dinâmicas e evoluem conforme os avanços em outras áreas. Esse fato pode ser comprovado por resultados alcançados nos últimos anos, como a atualização, em 1998, das tabelas de exigências nutricionais para suínos propostas pelo NRC (1988). Em condições brasileiras, as tabelas de exigências foram publicadas em 1992 e atualizadas em 2000 e 2005.

Entretanto, a maioria dos estudos para determinação das exigências de nutrientes ou avaliação de alimentos para suínos tem sido conduzida com animais alojados individualmente, ou em grupos de dois ou três animais por unidade experimental, conforme a categoria e a disponibilidade das instalações. Todavia, essa metodologia tem sido questionada, tornando-se ponto crítico na adoção dos resultados de pesquisa por suinocultores e empresas, uma vez que, em condições comerciais, os animais são mantidos em grupos maiores, de 20 ou até 100 animais do mesmo sexo por baia, em razão da utilização de comedouros modernos em sistemas automatizados.

Embora os resultados de alguns trabalhos comprovem que animais mantidos individualmente ou em pequenos grupos, como normalmente ocorrem em condições experimentais, expressem melhor seu potencial, poucos relatos têm sido feitos sobre as exigências nutricionais, o número ideal de animais por unidade experimental e o tipo de comedouro que deve ser utilizado em pesquisas visando aproximar os resultados experimentais aos da prática.

Assim, realizou-se este trabalho com o objetivo de avaliar os efeitos do número de animais por unidade experimental e do tipo de comedouro sobre as exigências nutricionais e características de carcaça de suínos dos 60 aos 95 kg.

\section{Material e Métodos}

O experimento foi conduzido nos galpões experimentais da granja de suínos da Empresa de Pesquisa Agropecuária de Minas Gerais (EPAMIG), localizados na Fazenda Experimental Vale do Piranga, município de Oratórios, Minas Gerais.
Os animais foram alojados em baias providas de comedouros semiautomáticos e de bebedouros tipo chupeta, em galpão de alvenaria com piso de concreto coberto com telhas de amianto. Um termômetro de máxima e mínima foi utilizado no interior do galpão para registro diário da temperatura.

Foram utilizados 704 suínos machos castrados, híbridos comerciais, selecionados geneticamente para deposição de carne magra na carcaça, com peso inicial de 59,84 $\pm 1,67 \mathrm{~kg}$, distribuídos em esquema de parcelas subdivididas, de modo que nas parcelas constaram os diferentes números de animais por unidade experimental (2 ou 20 animais) e nas subparcelas um esquema fatorial $2 \times 4$, com dois tipos de comedouro (linear semiautomático sem umidificador de ração e semi-automático conjugado com bebedouros) e quatro níveis de lisina digestível (0,75; 0,85 e 0,95 e 1,05\% de lisina digestível/kg de ração), em delineamento de blocos ao acaso com quatro repetições. Na formação de blocos, que foram repetições no tempo, utilizou-se como critério o peso inicial dos animais.

Água e ração foram fornecidas à vontade. As rações experimentais foram formuladas para atender ou exceder as exigências de suínos na fase de terminação, de acordo com Rostagno et al. (2005) para todos os nutrientes, exceto lisina. As rações foram constituídas de milho e farelo de soja, suplementadas com minerais, vitaminas e promotor de crescimento (Tabela 1). Nas unidades experimentais com os comedouros lineares, foi mantida a mesma área linear de comedouro por animal, ou seja, foram utilizados comedouros lineares semiautomáticos constituídos de duas bocas com $48 \mathrm{~cm}$ de comprimento linear por comedouro $(20 \mathrm{~cm}$ lineares de área livre para cada animal).

Os animais foram pesados no início e ao final de cada fase do período experimental, enquanto as rações e as sobras foram pesadas semanalmente até o final do experimento, quando os animais da unidade experimental atingiram o peso médio de $95 \mathrm{~kg}$, para determinação do ganho de peso, do consumo da ração e da conversão alimentar.

Ao final do período experimental, todos os animais foram colocados em jejum alimentar por aproximadamente 12 horas e encaminhados ao Frigorífico Vale do Piranga (FRIVAP) localizado no município de Ponte Nova, Minas Gerais, insensibilizados, abatidos e submetidos à avaliação das características de carcaça. As carcaças foram individualmente avaliadas com auxílio de uma pistola tipificadora Stork-SFK (modelo S87), utilizando o sistema informatizado "Fat-o-Meater Fom". A pistola foi introduzida na altura da 3a vértebra dorsal, transpassando o toucinho e o músculo Longissimus dorsi. 
Foram obtidos dados de espessura de toucinho, peso da carcaça quente, porcentagem de carne magra e quantidade de carne magra na carcaça. Os dados médios de carcaça em cada bloco foram considerados uma repetição.

As análises dos ingredientes das rações foram realizadas de acordo com o método descrito por Silva (1990), no Laboratório de Nutrição Animal do Departamento de Zootecnia da Universidade Federal de Viçosa (UFV).

Tabela 1 - Composição das rações experimentais

\begin{tabular}{|c|c|c|c|c|}
\hline \multirow[t]{2}{*}{ Ingrediente (\%) } & \multicolumn{4}{|c|}{ Nível de lisina digestível (\%) } \\
\hline & 0,75 & 0,85 & 0,95 & 1,05 \\
\hline Milho & 70,106 & 70,106 & 70,106 & 70,106 \\
\hline Farelo soja & 24,379 & 24,379 & 24,379 & 24,379 \\
\hline Amido de milho & 1,3000 & 1,1060 & 0,8260 & 0,512 \\
\hline Óleo de soja & 2,000 & 2,000 & 2,000 & 2,000 \\
\hline L-lisina $\mathrm{HCl}(78,5 \%)$ & 0,00 & 0,126 & 0,251 & 0,376 \\
\hline L-treonina $(98,5 \%)$ & 0,00 & 0,027 & 0,096 & 0,166 \\
\hline DL-metionina (99\%) & 0,00 & 0,038 & 0,103 & 0,168 \\
\hline L-triptofano (99\%) & 0,00 & 0,003 & 0,024 & 0,045 \\
\hline L-valina (99\%) & 0,00 & 0,00 & 0,00 & 0,045 \\
\hline Suplemento vitamínico ${ }^{1}$ & 0,200 & 0,200 & 0,200 & 0,200 \\
\hline Suplemento mineral ${ }^{2}$ & 0,200 & 0,200 & 0,200 & 0,200 \\
\hline Fosfato bicálcico & 0,850 & 0,850 & 0,850 & 0,850 \\
\hline Calcário & 0,543 & 0,543 & 0,543 & 0,543 \\
\hline Sal & 0,362 & 0,362 & 0,362 & 0,362 \\
\hline Tilosina & 0,050 & 0,050 & 0,050 & 0,050 \\
\hline ВНT & 0,010 & 0,010 & 0,010 & 0,010 \\
\hline Total & 100,00 & 100,00 & 100,00 & 100,00 \\
\hline \multicolumn{5}{|l|}{ Composição calculada } \\
\hline Proteína bruta (\%) & 16,85 & 17,01 & 17,23 & 17,48 \\
\hline Energia metabolizável (kca & kg)3.322 & 3.324 & 3.327 & 3.330 \\
\hline Lisina total $(\%)$ & 0,846 & 0,946 & 1,046 & 1,146 \\
\hline Lisina digestível (\%) & 0,750 & 0,850 & 0,950 & 1,050 \\
\hline $\begin{array}{l}\text { Metionina + cistina } \\
\text { digestível (\%) }\end{array}$ & 0,507 & 0,544 & 0,608 & 0,672 \\
\hline Treonina digestível (\%) & 0,560 & 0,586 & 0,655 & 0,724 \\
\hline Triptofano digestível (\%) & 0,176 & 0,178 & 0,199 & 0,220 \\
\hline Valina digestível (\%) & 0,713 & 0,713 & 0,713 & 0,745 \\
\hline Cálcio (\%) & 0,484 & 0,484 & 0,484 & 0,484 \\
\hline Fósforo disponível (\%) & 0,248 & 0,248 & 0,248 & 0,248 \\
\hline
\end{tabular}

${ }^{1}$ Quantidade/kg dieta: vit. A - 2.800 .000 UI; vit. $\mathrm{D}_{3}-600.000$ UI; vit. E $4.400 \mathrm{mg}$; vit. K3 - $1.000 \mathrm{mg}$; tiamina - $400 \mathrm{mg}$; riboflavina - $1.400 \mathrm{mg}$; piridoxina - $400 \mathrm{mg}$; vit. $\mathrm{B}_{12}-6.000 \mathrm{mcg}$; colina - $36 \mathrm{~g}$; biotina - $16 \mathrm{mg}$; ácido pantotênico - $4.800 \mathrm{mg}$; niacina - $10.000 \mathrm{mg}$; Se - $81 \mathrm{mg}$; BHT - $3.130 \mathrm{mg}$.

${ }^{2}$ Quantidade/kg dieta: ferro - 37,44 g; cobre - 73,75 g; zinco - 60 g; manganês $16,16 \mathrm{~g}$; iodo - $790 \mathrm{mg}$; cálcio - $148 \mathrm{~g}$.

${ }^{3}$ Segundo Rostagno et al. (2005).
Os dados de desempenho e composição de carcaça foram analisados por meio de análise de variância e regressão utilizando-se o Sistema de Análise Estatística e Genéticas SAEG (UFV, 2000). Para o fator qualitativo, as médias foram comparadas utilizando-se o teste de $\mathrm{F}$ e/ou Tukey adotando o nível de $5 \%$ de probabilidade. Para os fatores quantitativos os modelos foram escolhidos com base na significância dos coeficientes de regressão utilizando-se o teste de $\mathrm{t}$ e adotando-se o nível de 5\% de probabilidade no coeficiente de determinação $\left(r^{2}=\right.$ SQRegressão/SQTratamento) e no fenômeno biológico.

\section{Resultados e Discussão}

Não ocorreu interação $(\mathrm{P}>0,05)$ níveis de lisina digestível na ração $\times$ tipo de comedouro $\times$ número de animais na unidade experimental para as características de desempenho avaliadas (Tabela 2). O consumo diário de ração não foi influenciado $(\mathrm{P}>0,05)$ pelos níveis de lisina digestível. Resultado semelhante foi obtido por Friesen et al. (1995), Cline et al. (2000), Fontes et al (2000) e Abreu et al. (2007), que também não observaram influência do nível de lisina sobre o consumo de ração em suínos em terminação. Por outro lado, Kill et al. (2003) constataram, em experimento com suínos em terminação, variação significativa no consumo com o aumento do nível de lisina.

O resultado deste estudo está coerente com o obtido por Owen et al. (1994), que constataram que suínos machos castrados e fêmeas na fase de terminação foram ineficientes para regular o consumo voluntário de ração em diversos níveis de lisina.

Os níveis de lisina digestível influenciaram $(\mathrm{P}<0,05) \mathrm{o}$ ganho de peso, que aumentou de maneira linear, segundo equação $\hat{\mathrm{Y}}=867,018+208,895 \mathrm{X}, \mathrm{r}^{2}=0,96$. Efeito positivo dos níveis de lisina sobre o ganho de peso de suínos em terminação também foi observado por Souza Filho (2000), Cline et al. (2000), Main et al (2003) e Abreu et al. (2007). Entretanto, Kill et al. (2003) não verificaram variação significativa do GPD quando utilizaram leitoas de alto

Tabela 2 - Desempenho de suínos machos castrados selecionados para deposição de carne magra na carcaça alimentados com rações com diversos níveis de lisina digestível na fase dos 60 aos $95 \mathrm{~kg}$

\begin{tabular}{lcccc}
\hline Variável & \multicolumn{3}{c}{ Nível de lisina digestível (\%) } & CV (\%) \\
\cline { 2 - 4 } & 0,75 & 0,85 & 0,95 & 1,05 \\
\hline Consumo de ração (g/dia) & $2.762,66$ & $2.739,35$ & $2.716,16$ & $2.733,80$ \\
Ganho de peso (g/dia) $^{1}$ & $1.018,8$ & $1.050,8$ & $1.067,6$ & $1.082,8$ \\
Consumo de lisina (g/dia) $^{1}$ & 20,7 & 23,3 & 25,8 & 28,7 \\
Conversão alimentar (g/g) $^{1}$ & 2,74 & 2,65 & 2,56 & 10,61 \\
\hline
\end{tabular}

${ }^{1}$ Efeito linear $(\mathrm{P}<0,05)$. 
potencial genético para deposição de carne magra na carcaça e níveis crescentes de lisina na ração dos 65 aos $95 \mathrm{~kg}$.

$\mathrm{O}$ valor de ganho de peso médio de $1.055 \mathrm{~g} /$ dia obtido neste trabalho foi próximo ao encontrado por Hanh et al. (1995), Oliveira et al. (2003a), Arouca et al. (2007), que correspondem, respectivamente, a 1.065, 1.063 e $1.022 \mathrm{~g} /$ dia. Em contrapartida, Abreu et al. (2007) verificaram ganho de peso médio superior (1.132 g/dia).

A diferença de resultados observados entre trabalhos para ganho de peso médio diário pode estar relacionada aos diferentes grupos genéticos utilizados em cada trabalho, ao sistema de alimentação (Stahly et al. 1991), ao perfil e/ou aos níveis de aminoácidos, ao estado de saúde dos animais, à faixa de peso e ao sexo dos animais utilizados.

Foi observado efeito $(\mathrm{P}<0,05)$ dos tratamentos sobre o consumo de lisina digestível, que aumentou de forma linear à medida que se elevou o nível desse aminoácido na ração, segundo equação $\hat{\mathrm{Y}}=0,801559+26,4741 \mathrm{X}, \mathrm{r}^{2}=0,99$. Aumento linear no consumo de lisina digestível por suínos na fase de terminação, conforme a concentração desse aminoácido na ração, também foi relatado por Fontes et al. (2000), Cline et al. (2000), King et al. (2000) e Abreu et al. (2007).

O fato de o consumo diário de ração não ter variado significativamente entre os tratamentos justifica a variação linear positiva entre o consumo de lisina digestível com sua concentração na ração.

A conversão alimentar (CA) dos animais foi influenciada $(\mathrm{P}<0,05)$ de forma linear, segundo a equação $\hat{\mathrm{Y}}=3,22643-0,666028 \mathrm{X}\left(\mathrm{r}^{2}=0,92\right)$, pelos níveis de lisina digestível na ração. Embora a conversão alimentar tenha melhorado de forma linear, o modelo Linear Response Plateau (LRP) foi o que melhor se ajustou aos dados, estimando em $0,96 \%$ o nível de lisina digestível a partir do qual ocorreu um plateau (Figura 1), em um consumo diário correspondente de 26,1g de lisina digestível.

O nível de lisina digestível de $0,96 \%$ que proporcionou a melhor conversão alimentar neste trabalho foi semelhante ao observado por Abreu et al. (2007), que estimaram em $0,93 \%$ de lisina digestível correspondente a um consumo diário de 26,22 g. Entretanto, foi superior aos obtidos por Arouca et al. (2005, 2007), que obtiveram 0,72\% e 0,61\% de lisina total, respectivamente, e por Oliveira et al. (2003a,b), que obtiveram 0,76 e $0,80 \%$ de lisina total, respectivamente, em pesquisa com suínos na fase de terminação.

A variação de resultados entre os estudos pode estar relacionada, entre outros fatores, ao potencial genético dos animais para crescimento. Segundo O'Connell et al. (2006),

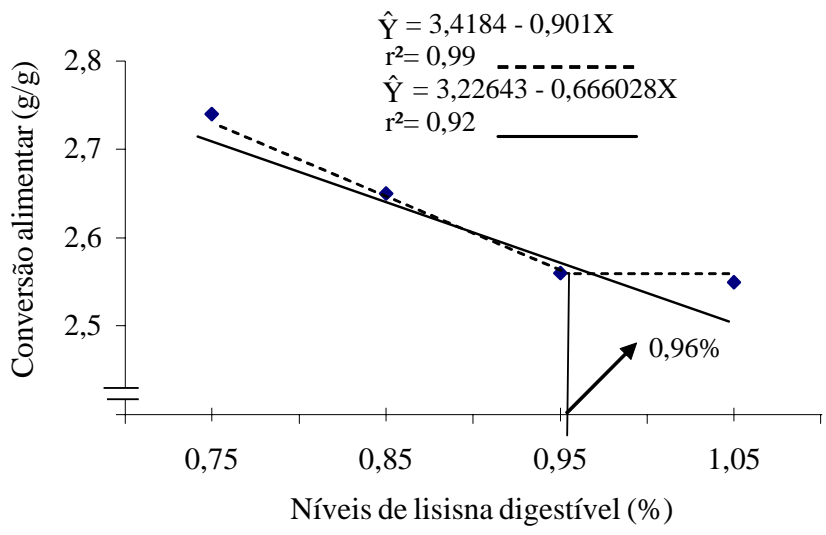

Figura 1 - Conversão alimentar de suínos machos castrados selecionados para deposição de carne magra na carcaça alimentados na fase dos 60 aos 95 kg com rações com diversos níveis de lisina.

a exigência de lisina de suínos varia de acordo com seu potencial de crescimento.

Considerando os resultados de desempenho dos animais, os níveis de lisina preconizados pelo NRC (1998) e por Rostagno et al. (2005), que correspondem, respectivamente, a 0,66 e 0,81\% de lisina digestível, provavelmente não atendem à exigência de suínos machos castrados de alto potencial de deposição de carne magra para ótimo desempenho.

O consumo de ração e o consumo de lisina médio diário não foram influenciados $(\mathrm{P}>0,05)$ pelo tipo de comedouro na unidade experimental (Tabela 3). Com esses resultados, pode-se deduzir que os tipos de comedouros estudados não comprometeram a ingestão voluntária de alimento dos animais.

Considerando o relato de Morgan et al. (1999) de que o consumo voluntário de suínos depende principalmente do número de visitas ao comedouro, do consumo por visita e do tempo de duração da visita, é possível que a diferença de espaço de comedouro por animal entre os dois tipos de comedouros avaliados, principalmente quando se utilizaram 20 animais por baia, foi compensada pelas alterações no número de visitas e na quantidade de ração consumida por visita ao comedouro.

Essa hipótese confirma os resultados de Hyun \& Ellis (2002), que avaliaram o padrão de consumo de suínos mantidos em grupos de 2, 4, 8 e 12 animais por baia e não observaram variação de desempenho, porém verificaram que o padrão de consumo foi significativamente modificado, pois o número de visitas diminuiu e o tempo por visita ao comedouro aumentou com o número de animais por baia. 
Tabela 3 - Desempenho de suínos machos castrados selecionados para deposição de carne magra na carcaça criados com dois tipos de comedouros e número de animais na unidade experimental na fase dos 60 aos $95 \mathrm{~kg}$

\begin{tabular}{lccc}
\hline Variável & \multicolumn{2}{c}{ Tipo de comedouro } & \multirow{2}{*}{ CV (\%) } \\
\cline { 2 - 3 } & Linear & $\begin{array}{c}\text { Conjugado com } \\
\text { bebedouros }\end{array}$ \\
\hline Consumo de ração (g/dia) & $2.777,9$ & $2.698,1$ & 10,64 \\
Ganho de peso (g/dia) & $1.045,9$ & $1.064,1$ & 9,91 \\
Consumo de lisina (g/dia) & 24,9 & 24,31 & 10,59 \\
Conversão alimentar (g/g) & 2,68 & 2,56 & 11,36 \\
\hline
\end{tabular}

Número de animais por unidade experimental

\begin{tabular}{|c|c|c|c|}
\hline & & \\
\hline & 2 & 20 & \\
\hline Consumo de ração (g/dia) & $2.738,5$ & $2.737,4$ & 10,64 \\
\hline Consumo de lisina (g/dia) & 24,61 & 24,64 & 10,59 \\
\hline Ganho de peso $(\mathrm{g} / \mathrm{dia})^{1}$ & $1.123,7 \mathrm{~A}$ & $986,3 \mathrm{~B}$ & 9,91 \\
\hline Conversão alimentar $(\mathrm{g} / \mathrm{g})^{2}$ & $2,46 \mathrm{~B}$ & $2,78 \mathrm{~A}$ & 11,36 \\
\hline
\end{tabular}

$\overline{1,2}$ Médias com letras distintas na mesma linha diferem, respectivamente $(\mathrm{P}<0,05)$ e $(\mathrm{P}<0,07)$ pelo teste $\mathrm{F}$.

Não foi observado efeito $(\mathrm{P}>0,05)$ dos tipos de comedouro sobre o ganho de peso e a conversão alimentar dos animais. Esses resultados estão coerentes com o fato de não ter ocorrido variação significativa nos consumos de ração e de lisina, cujas médias diárias não variaram ( $\mathrm{P}>0,05)$ entre unidades experimentais, portanto não foram influenciados (Tabela 3).

O consumo médio de ração, de $2.738 \mathrm{~g} / \mathrm{dia}$, foi semelhante aos obtidos por Cline et al. (2000), Moreira et al. (2002) e Abreu et al. (2007), que corresponderam, respectivamente, a 2.730, 2.639 e $2.853 \mathrm{~g} /$ dia. Pode-se deduzir, então, que o número de animais na unidade experimental não comprometeu a ingestão voluntária de alimento. Esses resultados diferem do observados por Ferguson \& Lavers (2000) e Ferguson et al. (2001), que constataram que animais mantidos individualmente tiveram consumo de ração diário superior ao daqueles mantidos em grupos de 7 ou 13 animais por baia. Diferem ainda dos observados por Gonyou \& Stricklin (1998), que verificaram redução significativa no consumo diário de ração quando compararam animais mantidos em grupos de 7 e 10 ou grupos de 3 e 5 animais/baia.

O ganho de peso médio diário variou $(\mathrm{P}<0,05)$ entre os diferentes números de animais por UE e foi melhor nas unidades experimentais com dois animais. De forma semelhante, Gonyou \& Stricklin (1998) também observaram redução significativa no ganho de peso dos animais alojados em densidades de 7 ou 10 animais/baia em comparação aos alojados em densidades de 3 ou 5 animais/baia.
Comprometimento do ganho de peso de suínos em terminação alojados em maiores grupos por baia também foi verificado por Ferguson et al. (2001), Ferguson \& Lavers (2000) e Hyun \& Ellis (2002). Neste estudo, os animais alojados em densidade de 2 animais/unidade experimental apresentaram melhor $(\mathrm{P}<0,07)$ conversão alimentar em comparação àqueles alojados em densidade de 20 animais/ baia. Melhores resultados de conversão alimentar em suínos alojados em grupos menores na fase de terminação também foram verificados por Vansickle (2001), Edmonds et al. (1998) \& Chapple (1993).

Estudando o efeito do tamanho do grupo (10, 20, 40 e 80 suínos/baia) sobre o desempenho dos animais, com padronização de espaço, Schmolke \& Gonyou (2000) verificaram que nenhum dos parâmetros avaliados foi influenciado pelo número de animais por baia e concluíram que os suínos são eficientes em manter o desempenho quando se mantém a área recomendada por animal. Mais recentemente, Street \& Gonyou (2008) constataram que a redução do espaço por animal $\left(0,78 \times 0,52 \mathrm{~m}^{2}\right)$, e não o tamanho do grupo ( $18 \times 108$ animais), foi o fator determinante para redução do desempenho dos suínos em crescimento e terminação.

Assim, a piora na eficiência de utilização do alimento para ganho de peso dos animais mantidos em grupo de 20 observada neste estudo pode estar relacionada à menor área disponível por animal em comparação ao alojamento em grupo de dois, pois, de acordo com Paterson \& Pearce (1991), a piora na eficiência alimentar e a redução do crescimento com o estresse crônico são um mecanismo pelo qual os suínos suportam elevadas densidades de criação.

Com base nos resultados de ganho de peso e conversão alimentar, pode-se inferir que o número de animais por unidade experimental é um dos fatores que podem alterar o desempenho de suínos em terminação. Não houve interação ( $\mathrm{P}>0,05)$ entre os níveis de lisina na dieta, o tipo de comedouro e o número de animais na unidade experimental, pois a associação desses fatores não alterou as características de carcaça (Tabela 4).

A espessura de toucinho no ponto $\mathrm{P}_{2}\left(\mathrm{ETP}_{2}\right)$ não foi influenciada $(\mathrm{P}>0,05)$ pelos níveis de lisina digestível na ração. Resultado semelhante foi obtido por Friesen et al. (1994b), Hanh et al. (1995), Loughmiller et al. (1998), Souza Filho et al. (2000), Moreira et al. (2002), Oliveira et al. (2003a), Oliveira et al. (2003b), Arouca et al. (2005) e Arouca et al. (2007) em estudos conduzidos com suínos machos castrados e fêmeas na fase de terminação.

Cline et al. (2000), no entanto, observaram redução linear da espessura de toucinho com o aumento de lisina nas 
Tabela 4 - Características de carcaça de suínos machos castrados selecionados para deposição de carne magra na carcaça alimentados na fase de terminação com rações com diversos níveis de lisina digestível

\begin{tabular}{lcccr}
\hline Variável & \multicolumn{3}{c}{ Nível de lisina digestível (\%) } & \multicolumn{1}{c}{ CV (\%) } \\
\cline { 2 - 4 } & 0,75 & 0,85 & 0,95 & 1,05 \\
\hline Espessura de toucinho (mm) & 13,94 & 13,54 & 13,61 & 13,42 \\
Rendimento de carne magra (\%) & 56,11 & 56,39 & 56,40 & 56,55 \\
Quantidade de carne magra (kg) & 38,99 & 39,12 & 38,69 & 39,29 \\
Peso da carcaça (kg) & 67,98 & 69,42 & 68,72 & 69,53 \\
Rendimento de carcaça (\%) & 70,49 & 70,05 & 70,31 & 70,23 \\
\hline
\end{tabular}

dietas em fêmeas suínas em terminação. Hahn et al. (1995), trabalhando com fêmeas dos 72 aos 136 kg, observaram efeito quadrático da espessura de toucinho quando aumentaram os níveis de lisina digestível na ração.

O valor médio (13,6 mm) da ETP $_{2}$ obtido neste trabalho foi semelhante aos obtidos por Kill et al. (2003b), 13,65 mm, em pesquisa com fêmeas na fase de terminação tardia, e por Arouca et al. (2007), de 13,91 mm, em estudo com machos castrados dos 95 aos $122 \mathrm{~kg}$. Entretanto, esse valor médio foi superior aos obtidos por Kill et al. (2003a) e Abreu et al. (2007), que obtiveram, respectivamente, 11,15 e $11,94 \mathrm{~mm}$.

O rendimento de carne magra (RCM) não foi influenciado $(\mathrm{P}>0,05)$ pelos níveis de lisina da ração. Dados semelhantes foram observados por Souza Filho et al. (2000), Oliveira et al. (2003b) e Abreu et al (2007), que não observaram efeito dos níveis de lisina da ração sobre o rendimento de carne magra de suínos machos castrados na fase de terminação. Entretanto, Loughmiller et al. (1998), Cline et al. (2000) e Witte et al. (2000), em experimentos com leitoas em terminação tardia, observaram que o rendimento de carne magra aumentou de forma linear de acordo com os níveis de lisina. Trabalhando com suínos machos castrados e fêmeas dos 80 aos $120 \mathrm{~kg}$ para avaliar níveis de lisina digestível, Bertol et al. (2000) verificaram diminuição quadrática no rendimento de carne magra dos machos, enquanto nas fêmeas houve diminuição linear.

O valor médio de rendimento de carne magra obtido neste trabalho $(56,3 \%)$ foi superior aos resultados encontrado por Oliveira et al. (2003b), em suínos machos castrados selecionados para deposição de carne magra dos 110 aos 125 kg, e por Arouca et al. (2007), em suínos geneticamente selecionados para deposição de carne magra, dos 95 aos $122 \mathrm{~kg}$; esses autores encontraram, respectivamente, valores médios de 53,74 e 55,83\% de carne magra na carcaça. Valores de rendimento de carne magra inferiores ao obtido neste trabalho também foram verificados por Johnston et al. (1993), Loughmiller et al. (1998), Cline et al. (2000) e De la Llata et al. (2002), trabalhando com níveis de lisina para suínos em terminação tardia, que encontraram, respectivamente, valores médios de 50,58; 50,8; 46,96 e $50,07 \%$ de RCM.

O valor médio de rendimento de carne magra obtido neste trabalho foi inferior ao obtido por Bertol et al. (2000), $58,3 \%$, em machos castrados dos 80 aos $120 \mathrm{~kg}$, e aqueles de 57,9 e 59,16\%, respectivamente, determinados por Kill et al. (2003a) e Kill et al. (2003b) em fêmeas dos 65 aos 105 kg e dos 65 aos $115 \mathrm{~kg}$.

Os níveis de lisina digestível não influenciaram $(\mathrm{P}>0,05)$ a quantidade de carne magra (QCM). Resultado similar foi obtido por Souza Filho et al. (2000) e Oliveira et al. (2003b), que também não observaram efeito significativo dos níveis de lisina da ração sobre o rendimento de carne magra na carcaça de suínos machos castrados na fase de terminação tardia. Por outro lado, Lougmiller et al. (1998) e Cline et al. (2000) observaram aumento linear na quantidade de carne magra com o aumento dos níveis de lisina da ração em trabalho com fêmeas na fase de terminação tardia.

As variações nos valores de rendimento e quantidade de carne magra na carcaça entre os animais utilizados nos trabalhos refletem diferenças no potencial de crescimento e justificam a inconsistência de resultados quanto à demanda de lisina para melhores resultados de GPD e conversão alimentar dos animais.

Não foi observado efeito $(\mathrm{P}>0,05)$ dos níveis de lisina digestível sobre o peso da carcaça (PC). Resultados semelhantes foram observados Friesen et al. (1995), Souza Filho et al. (2000), Kill et al. (2003a,b), Oliveira et al. (2003a,b) ao avaliarem os níveis de lisina da dieta sobre o peso de carcaça para suínos machos e fêmeas na fase de terminação. De forma contrária, Gonçalves et al. (1999), trabalhando com machos castrados e fêmeas dos 60 aos $112 \mathrm{~kg}$, observaram aumento, enquanto Cline et al. (2000), trabalhando com fêmeas de 54 a 116 kg, observaram redução linear no peso da carcaça com o aumento do nível de lisina da ração.

O peso médio de carcaça $(69,1 \mathrm{~kg})$ determinado neste trabalho resultou em rendimento médio de carcaça igual a $70,27 \%$, valor próximo aos obtidos por Witte et al. (2000), de $71,72 \%$, porem inferiores aos obtidos por Johnston et al. (1993) e Cline et al. (2000), de 74,48 e 75,32\%. Essas diferenças 
no rendimento de carcaça entre os trabalhos podem estar associadas ao grupo genético e sexo dos animais e ao período de jejum antes do abate.

Verificou-se interação $(\mathrm{P}<0,05)$ entre o tipo de comedouro e o número de animais na unidade experimental para quantidade e rendimento de carne magra nas carcaças (Tabelas 5 e 6).

A espessura de toucinho de suínos híbridos comerciais consumindo diferentes níveis de lisina dos 60 aos $95 \mathrm{~kg}$ foi menor $(\mathrm{P}<0,07)$ quando os animais receberam a ração experimental nos comedouros lineares em relação àqueles alimentados em comedouros conjugados com bebedouros.

A variação na $\mathrm{ETP}_{2}$ dos animais atribuída ao tipo de comedouro utilizado na unidade experimental não está coerente com os resultados de consumo de ração e ganho de peso, que não variaram significativamente entre tipos de comedouros. Entretanto, o fato de os comedouros conjugados com bebedouros proporcionarem consumo de ração molhada pode ter contribuído para aumentar a espessura de toucinho dos animais que utilizaram esse tipo de comedouro.

Por outro lado, não houve variação $(\mathrm{P}>0,05)$ nos valores de peso e rendimento de carcaça dos animais entre os tipos de comedouro utilizados na unidade experimental.

A espessura de toucinho, o peso e rendimento de carcaça não foram influenciados $(\mathrm{P}>0,05)$ pelo número de animais na unidade experimental (Tabela 6). De maneira similar, O’Doherty \& Mckeon (2000) avaliaram diferentes espaços no comedouro e densidades de animais na baia 13 ou 16 animais por baia equivalendo, respectivamente a um espaço de 0,78 ou $0,65 \mathrm{~m}^{2}$ por animal - e observaram que o número de animais nas baias não influenciou a espessura de toucinho e o peso da carcaça de suínos em crescimento e terminação.

Tabela 5 - Características de carcaça de suínos machos castrados selecionados para deposição de carne magra na carcaça em função do tipo de comedouro, dos 60 aos $95 \mathrm{~kg}$

\begin{tabular}{|c|c|c|c|}
\hline \multirow[t]{2}{*}{ Variável } & \multicolumn{2}{|c|}{ Tipo de comedouro } & \multirow[t]{2}{*}{$\mathrm{CV}(\%)$} \\
\hline & Linear & $\begin{array}{c}\text { Conjugado com } \\
\text { bebedouros }\end{array}$ & \\
\hline Espessura de toucinho $(\mathrm{mm})^{1}$ & $13,23 \mathrm{~B}$ & $14,02 \mathrm{~A}$ & 12,45 \\
\hline Peso da carcaça (kg) & 68,92 & 68,90 & 3,71 \\
\hline \multirow[t]{3}{*}{ Rendimento de carcaça (\%) } & 70,33 & 70,21 & 3,10 \\
\hline & \multicolumn{2}{|c|}{$\begin{array}{l}\text { Número de animais por } \\
\text { unidade experimental }\end{array}$} & \\
\hline & 2 & 20 & \\
\hline Espessura de toucinho $(\mathrm{mm})$ & 14,04 & 13,21 & 12,45 \\
\hline Peso da carcaça (kg) & 69,89 & 67,93 & 3,71 \\
\hline Rendimento de carcaça (\%) & 70,90 & 69,64 & 3,10 \\
\hline
\end{tabular}

${ }^{1}$ Médias com letras distintas na mesma linha diferem $(\mathrm{P}<0,07)$ pelo teste $\mathrm{F}$.
Tabela 6 - Rendimento e quantidade de carne magra na carcaça de suínos machos castrados selecionados para deposição de carne magra terminados em baias com dois tipos de comedouro e dois números de animais consumindo rações com diferentes níveis de lisina digestível

\begin{tabular}{|c|c|c|c|}
\hline \multirow[t]{2}{*}{$\begin{array}{l}\text { Tipo de } \\
\text { comedouro }\end{array}$} & \multicolumn{2}{|c|}{$\begin{array}{c}\text { Número de animais } \\
\text { na unidade experimental }\end{array}$} & \multirow[t]{2}{*}{ CV (\%) } \\
\hline & 2 & 20 & \\
\hline & Rendimento & magra (\%) & \\
\hline \multirow{3}{*}{$\begin{array}{l}\text { Linear } \\
\text { Conjugado com } \\
\text { bebedouros }\end{array}$} & $56,64 \mathrm{Aa}$ & $56,82 \mathrm{Aa}$ & 2,32 \\
\hline & $55,27 \mathrm{Ba}$ & 56,73Аа & 2,32 \\
\hline & Quantidade & magra $(\mathrm{kg})$ & \\
\hline Linear & 39,89Aa & 38,62Aa & 5,19 \\
\hline $\begin{array}{l}\text { Conjugado com } \\
\text { bebedouros }\end{array}$ & $38,25 \mathrm{Ba}$ & 39,33Аа & 5,19 \\
\hline
\end{tabular}

Wolter et al. (2001) avaliaram o efeito de diferentes grupos de suínos na fase de creche até a terminação (25, 50 e 100 animais por baia), mantendo o mesmo espaçamento (0,68 $\mathrm{m}^{2} /$ animal), e também observaram que a espessura de toucinho, o peso da carcaça quente e o rendimento de carcaça não foram influenciados pelo tamanho do grupo, e concluíram que o tamanho do grupo tem efeito limitado sobre as características de carcaça. Nesta pesquisa, o rendimento e a quantidade de carne magra na carcaça foram menores $(\mathrm{P}<0,05)$ quando utilizado o comedouro conjugado com bebedouros (Tabela 6). Entretanto, não apresentaram variação $(\mathrm{P}>0,05)$ com o aumento da densidade de 2 para 20 animais por unidade experimental em nenhum dos tipos de comedouro.

Os resultados de desempenho e das demais medidas de carcaça avaliadas não possibilitaram obter justificativa biológica para a redução do rendimento e da quantidade de carne na carcaça nos animais mantidos em pares em baias com comedouro conjugado com bebedouros.

\section{Conclusões}

Suínos de alto potencial de deposição de carne magra na carcaça na fase dos 60 aos $95 \mathrm{~kg}$ exigem 1,05 e 0,96\% de lisina digestível na ração, correspondente a consumos de lisina digestível de 28,7 e 26,1 g/dia, respectivamente, para melhor ganho de peso e conversão alimentar, independentemente do tipo de comedouro e do número de animais na unidade experimental. Na unidade experimental com dois suínos em terminação, o desempenho pode apresentar alterações, uma vez que os animais aumentam o ganho de 
peso e melhoram a conversão alimentar, mas não alteram significativamente os consumos de ração e lisina.

\section{Literatura Citada}

ABREU, M.L.T.; DONZELE, J.L.; OLIVEIRA, R.F.M. et al. Níveis de lisina digestível em rações, utilizando-se o conceito de proteína ideal, para suínos machos castrados de alto potencial genético para deposição de carne magra na carcaça dos 60 aos $95 \mathrm{~kg}$. Revista Brasileira de Zootecnia, v.36, n.1, p.54-61, 2007.

AROUCA, C.L.C.; FONTES, D.O.; VELOSO, J.A.F. et al. Exigências de lisina, com base no conceito de proteína ideal, para suínos machos castrados dos 96 aos $120 \mathrm{~kg}$, selecionados para eficiência de crescimento. Arquivo Brasileiro de Medicina Veterinária e Zootecnia, v.57, n.1, p.104-111, 2005.

AROUCA, C.L.C.; FONTES, D.O.; BAIÃO, N.C. et al. Exigências de lisina para suínos machos castrados selecionados geneticamente para deposição de carne magra na carcaça, dos 95 aos $122 \mathrm{~kg}$. Revista Ciência e Agrotecnologia, v.31, n.2, p.531-5939, 2007.

BERTOL, T.M.; LUDKE, J.V.; FRAIHA, M. et al. Determinação das exigências de lisina digestível para suínos machos castrados e fêmeas dos 80 aos $120 \mathrm{~kg}$ de peso vivo. In: REUNIÃO ANUAL DA SOCIEDADE BRASILEIRA DE ZOOTECNIA, 37., 2000, Viçosa, MG. Anais...Viçosa, MG: Sociedade Brasileira de Zootecnia, 2000. (CD-ROM).

BRUMM, M.C.; GONYOU, H.W. Effect of facility design on behavior and feed and walter intake. In: LEWIS A.; SOUTHERN, L.L. (Eds.) Swine nutrition. 2.ed. Boca Raton: CRC Press, 2001. p.499-518.

BRUMM, M.C.; BAYSINGER, A.K.; WILLS, R.W. et al. Effect of wean-to-finish management on pig performance. Journal of Animal Science, v.80, p.309-315, 2002.

CLINE, T.R.; CROMWELL, G.L.; CRENSHAW, T.D. et al. Further assessment of the dietary lysine requirement of finishing gilts. Journal of Animal Science, v.78, n.4, p.987-992, 2000.

DE LA LLATA, M.; DRITZ, S.S.; TOKACH, M.D. et al. Effects of increasing L-lysine $\mathrm{HCl}$ in corn- or sorghum-soybean mealbased diets on growth performance and carcass characteristics of growing-finishing pigs. Journal of Animal Science, v.80, n.9, p.2420-2432, 2002.

DOURMAD, J.Y.; GUILLOU, D.; SÈVE, B. et al. Response to dietary lysine supply during the finishing period in pigs. Livestock Production Science, v.45, n.2/3, p.179-186, 1996.

EDMONDS, M.S.; ARENTSON, B.E.; MENTE, G. Effect of protein levels and space allocations on performance of growing-finishing pigs. Journal of Animal Science, v.76, p.814-821, 1998.

FERGUSON, N.S.; LAVERS, G.A. Stress: should animals be fed to their potential requirements? South African Journal of Animal Science, v.30, p.42-44, 2000 (suppl. 1).

FERGUSON, N.S.; LAVERS, G.A.; GOUS, R.M. The effect of stocking density on the responses of growing pigs to dietary lysine. Animal Science, v.73, p.459-469, 2001.

FONTES, D.O.; DONZELE, J.L; FERREIRA, A.S. et al. Níveis de lisina para leitoas selecionadas geneticamente para deposição de carne magra, dos 60 aos $95 \mathrm{~kg}$. Revista Brasileira de Zootecnia, v.29, n.3, p.784-793, 2000.

FRIESEN, K.G.; NELSSEN, J.L.; GOODBAND, R.D. et al. The effect of dietary lysine on growth, carcass composition, and lipid metabolism in high-lean growth gilts fed from 72 to 136 kilograms. Journal of Animal Science, v.73, n.11, p.3392-3401, 1995.

GONYOU, H.W.; STRICKLIN, R. [1997]. Space requirements determned for growing-finishing pigs. The Newsletter of Prairie Swine Centre Inc. Disponível em: <http://www.aginfonet.com /agricarta/content/prairie_swinr_centre/finishing_pigs.html Acesso em: 4/9/2004.

GONYOU, H.W.; STRICKLIN, R. Effects of floor area allowance and group size on the productivity of growing/finishing pigs. Journal of Animal Science, v.76, p.1326-1330, 1998.
HAHN, J.D.; BIEHL, R.R.; BAKER, D.H. Ideal digestible lysine level for early- and late-finishing swine. Journal of Animal Science, v.73, n.3, p.773-784, 1995.

HYUN, Y.; ELLIS, M.; RISKOWSKI, G. et al. Growth performance of pigs subjected to multiple concurrent environmental stressors. Journal of Animal Science, v.76, p.721-727, 1998.

HYUN, Y.; ELLIS, M. Effect of group size and type feeder on growth performance and feeding patterns in finishing pigs. Journal of Animal Science, v.80, p.568-574, 2002.

HOLCK, J.T.; SCHINCKEL, A.P.; COLEMAN, J.L. et al. An Evaluation of growth performance in swine raised in commercial and unrestricted environments. Purdue University, Swine Day, september, 1998.

KILL, J.L.; DONZELE, J.L.; OLIVEIRA, R.F.M. et al. Níveis de lisina para leitoas com alto potencial genético para deposição de carne magra dos 65 aos $95 \mathrm{~kg}$. Revista Brasileira de Zootecnia, v.32, n.6, p.1647-1656, 2003 (supl.1).

KILL, J.L; DONZELE, J.L; OLIVEIRA, R.F.M. et al. Planos de nutrição para leitoas com alto potencial genético para deposição de carne magra dos 65 aos 105 kg. Revista Brasileira de Zootecnia, v.32, n.6, p.1330-1338, 2003.

KROHN, T.C.; ELLEGAARD, L.; HANSEN, A.K. A preliminary study of the impact stocking density on the behaviour of group housed Göttingen minipigs. Scandinavian Journal of Laboratory Animal Science, v.27, n.4, 2000.

MORGAN, C.A.; NIELSEN, B.L.; LAWRENCE, A.B. et al. Describing the social environment and its effects on food intake and growth. In: KYRIAZAKIS, I. (Ed.) A quantitative biology of the pig. Wallingford: Cabi Publishing, 1999. p.99-125.

MOREIRA, I.; GASPAROTTO, L.F.; FURLAN, A.C. et al. Exigência de lisina para machos castrados de dois grupos genéticos de suínos na fase de terminação, com base no conceito de proteína ideal. Revista Brasileira de Zootecnia, v.31, n.1, p.96-103, 2002.

NIELSEN, B.L.; LAWRENCE, A.B.; WHITTEMORE, C.T. Effect of group size on feeding behaviour, social behaviour, and performance of growing pigs using single-space feeders. Livestock Production Science, v.44, p.73-85, 1995.

NATIONAL RESEARCH COUNCIL - NRC. Nutrient requeriments of swine. 9.ed. Washington, D.C.: National Academy Press, 1998. 93p.

O'CONNEL, M.K.; LYNCH, P.B.; O'DOHERLY, J.V. et al. Determination of the optimum dietary lysine concentration for boars and gilts penned in pairs and in groups in the weight range 60 to $100 \mathrm{~kg}$. Animal Science, v.82, p.65-73, 2006.

O’DOHERTY, J.V.; McKEON, M.P. Effect of nutrient density and group size on the performance of growing and finishing pigs given food using single-space feeders. Animal Science, v.71, p. 281-288, 2000.

OLIVEIRA, A.L.S.; DONZELE, J.L.; OLIVEIRA, R.F.M. et al. Lisina para suínos machos castrados de alto potencial genético para deposição de carne magra dos 95 aos $110 \mathrm{~kg}$. Revista Brasileira de Zootecnia, v.32, n.2, p.337-343, 2003a.

OLIVEIRA, A.L.S.; DONZELE, J.L.; OLIVEIRA, R.F.M. et al. Lisina em rações para suínos machos selecionados para deposição de carne magra na carcaça dos 110 aos $125 \mathrm{~kg}$. Revista Brasileira de Zootecnia, v.32 n.1, p.150-155, 2003b.

PATERSON, A.M.; PEARCE, G.P. The effect of space restriction during rearing on growth and cortisol levels of male pigs. In: BATTERHAM, E.S. (Ed.). Manipulating pig production III. Attwood: Australasian Pig Science Association, 1991. p.68.

OWEN, K.Q.; KNABE, D.A; BURGOON, K.G. et al. Self-selection of diets and lysine requirements of growing finishing swine. Journal of Animal Science, n.72, p.554-564, 1994.

QUINIOU, N.; DUBOIS, S.; NOBLET, J. Voluntary feed intake and feeding behaviour of group-housed growing pigs are affected by ambient temperature and body weight. Livestock Production Science, v.63, p.245-253, 2000.

SCHARLACH, W. Focus on feed conversion. Disponível em: http:// www.afma.co.za/AFMA_Template/1,2491,765_414,00.htmalAFMA Matrix. Acesso em: 28/11/2002. 
SCHMOLKE, S.A.; GONYOU, H.W. Effect of group sizes of $10,20,40$ and 80 pigs on productivit during the growerfinisher period. Advances in Pork Production, v.11, 2000 (abst.).

SILVA, D.J. Análise de alimentos (métodos químicos e biológicos). Viçosa, MG: Universidade Federal de Viçosa, 1990, 165p.

SMITH, L.; PATIENCE, J.F.; GONYOU, H.W. et al. The impact of feeder adjustment and floor space allowance on the performance of nursery pigs. Advances in Pork Production, v.13, 2002 (abst. 22).

SOUZA FILHO, G.A.; LIMA, J.A. F.; FIALHO, E.T. et al. Efeito de planos de nutrição e de genótipos sobre características físicas de carcaça de suínos. Ciência e Agrotecnologia, v.24, n.4, p.1060-1067, 2000.

STAHLY, T.S.; CROMWELL, G.L.; TERHUNE, D. Responses of high, medium and low lean growth genotypes to dietary amino acid regimen. Journal of Animal Science, v.69, p.364, 1991. (suppl. 1) (Abstr.).
STREET, B.R.; GONYOU, H.W. Effects of housing finishing pigs in two group sizes and at two floor space allocations on production, health, behavior, and physiological variables. Journal of Animal Science, v.86, n.4, p.982-991, 2008.

UNIVERSIDADE FEDERAL DE VIÇOSA - UFV. SAEG (Sistemas de Análises Estatísticas e Genéticas). (Versão 8.0). Viçosa, MG: 2000.

VANSICKLE, J. [2001]. Wean-to-finish systems: Researchers Play Catch-Up. Farmweld. Disponível em:< http://www.farmweld. com/news/nationalhog/wean-to-finish-systems.html.> Acesso em: 8/11/2002.

WOLTER, B.F.; ELLIS, M.; CURTIS, S.E. et al. Effects of group size, floor space on pigs evaluated. Feedstuffs, p.8-13, 2000.

WOLTER, B.F.; ELLIS, M.; CURTIS, S.E. et al. Effects of group size on pig performance in a wean-to-finish production system. Journal of Animal Science, v.79, p.1067-1073, 2001.

ZIJLSTRA, R.T.; SCOTT, T.A. Feed evaluation and feed intake. Advances in Pork Production, v.11, p.221-224, 2000. 